\title{
Raman Microspectroscopy of LiDNA Fibres in Ethanol and tert-Butanol
}

\author{
J. Mud,* C. Otto, F. F. M. de Mul and J. Greve \\ Twente University of Technology, Department of Applied Physics, P.O. Box 217, 7500 AE Enschede, The Netherlands
}

\begin{abstract}
The conformation of low-salt LiDNA in fibrous form has been studied by Raman microspectroscopy. The recorded spectrum of a fibre soaked in ethanol is very similar to that of a fibre at low relative humidity. From $x$-ray experiments it is known that in the latter case the DNA adopts the $C$ conformation. Therefore, it can be concluded that this is also the case in a low-salt LiDNA fibre soaked in ethanol. Further, it has been observed that the DNA conformation did not change when the excess ethanol was allowed to evaporate. The $\mathrm{C}$ form is also found when the fibre is in contact with ethanol vapour only. These results are in agreement with $x$-ray studies. However, our experiments with a LiDNA fibre in tert-butanol are not in agreement with $\mathrm{x}$-ray results. Only when the tert-butanol is absolutely free from water is a state intermediate between the $B$ and $C$ forms found.
\end{abstract}

\section{INTRODUCTION}

Using different techniques many experiments have been performed to determine the conformation of DNA under various conditions. From these measurements it follows that both the sodium and lithium salts of DNA in aqueous low-salt solutions will adopt the B form. When DNA is brought into a fibrous form the sodium and lithium salts (NaDNA and LiDNA) show different behaviour. The NaDNA fibre can be transformed from the $\mathrm{C}$ form at low relative humidity (r.h.) $(33 \%)$ through the A conformation (at r.h. 79\%) to the B form (r.h. $98 \%$ ), whereas the LiDNA fibre at low r.h. is in the C form, transforming to the B conformation at r.h. $79 \%$ or higher. ${ }^{1}$

In water-alcohol mixtures the two fibres also behave differently: a low-salt sodium fibre immersed in such a mixture undergoes a $\mathrm{B} \rightarrow \mathrm{A}$ transition when the mixture contains at least 72 vol.- $\%$ of ethanol. ${ }^{2,3}$ However, the low-salt fibre of LiDNA shows a $\mathrm{B} \rightarrow \mathrm{C}$ transition, the latter form being adopted at $95 \mathrm{vol} . \mathrm{\%}$ of ethanol, whereas between 70 and 95 vol. $\%$ of ethanol a mixture of these conformations may be present. This was shown by Zimmerman and Pheiffer' using the $\mathrm{x}$-ray technique. Many circular dichroism (CD) spectra seem to prove that concentrated salt solutions and several organic solvents convert DNA to the C conformation. However, Zimmerman and Pheiffer ${ }^{1}$ showed that for fibres this was only the case in a very limited number of cases.

The Raman technique provides another source of information for the determination of DNA conformations and it has an important advantage because spectra can be recorded of crystals, fibres, films, gels and solutions. Whereas $\mathrm{x}$-ray experiments can only be performed with crystals and fibres and circular dichroism studies, NMR and absorption spectroscopy are mostly limited to solutions, Raman spectroscopy can contribute to the knowledge of the conformation of DNA in all the mentioned physical states. Raman scattering may therefore be used to close the gap between $\mathrm{x}$-ray and $\mathrm{CD}$ studies

\footnotetext{
* Author to whom correspondence should be addressed.
}

and solve the apparent controversy regarding the results of these techniques.

However, very few Raman spectra of the $C$ form have been published. Goodwin and Brahms ${ }^{4}$ and Erfurth et $a l^{5}$ recorded the spectrum of a low-salt fibre of LiDNA at low relative humidity $(47 \%$ and $33 \%)$, whereas Marvin et al. ${ }^{6}$ have shown by $\mathrm{x}$-ray experiments that such a fibre adopts the $\mathrm{C}$ conformation. We have confirmed their results and have also recorded the Raman spectra of LiDNA fibres immersed in ethanol and tert-butanol and also in contact with ethanol vapour.

\section{MATERIALS AND METHODS}

Calf thymus DNA (Sigma) was dissolved in a $20 \mathrm{~mm}$ EDTA solution, dialysed first for $24 \mathrm{~h}$ against $1 \mathrm{M} \mathrm{LiCl}$ and then 3-5 times against $1 \mathrm{~mm} \mathrm{LiCl}$. In order to produce a fibre from the DNA solution, two glass spheres of diameter $2 \mathrm{~mm}$ melted on thin rods were placed opposite each other, a drop of solution containing 2-3 wt-\% of DNA was brought between the spheres and then the spheres were slowly pulled apart. By drying out the solution a fibre was formed with an average length of $3 \mathrm{~mm}$ and a diameter of $200 \mu \mathrm{m}$.

The fibre was placed on a sapphire substrate in a vessel that was filled with alcohol and sealed. The sample stayed in contact with the fluid. Alternatively, in some experiments the alcohol was allowed to evaporate to such an extent that the fibre was in contact with alcohol vapour only. The ethanol (Merck, 99.8\%) was used without purification but the tert-butanol (BDH Chemicals, 95\%) was distilled twice with calcium chloride added.

Raman spectra of the fibres were recorded by using a microprobe arrangement. The beam from an argon ion laser (Coherent Radiation CR3, $\lambda=514.5 \mathrm{~nm}$ ) was focused to a spot at the entrance diaphragm of a Nikon Optiphot microscope. This spot was imaged on to the surface of the fibre by an objective (Spindler and Hoyer, $M=40 \times$, N.A. $=0.65$ ) so that the illuminated area of the fibre had a diameter of $4 \mu \mathrm{m}$. The same objective 
collected the scattered light and the spot on the fibre was imaged on to the entrance slit of a double monochromator (Jobin-Yvon, Ramanor HG2S). The Raman signal was detected by a photon-counting system consisting of a photomultiplier (EMI 9863B), an amplifierdiscriminator and a 32-bit counter.

The measurements were controlled by a Digital Equipment LSI 11/02 minicomputer and the data were stored on floppy disk. The laser power impinging on the fibre was typically $10 \mathrm{~mW}$ and the slits of the monochromator had a width of $400 \mu \mathrm{m}$, corresponding to a spectral resolution of $3.2 \mathrm{~cm}^{-1}$.

The spectra were recorded between 600 and $1600 \mathrm{~cm}^{-1}$ at intervals of $2 \mathrm{~cm}^{-1}$; the counting time at each point was $25 \mathrm{~s}$.

\section{RESULTS}

The Raman spectrum of a LiDNA fibre in contact with ethanol vapour is shown in Fig. 1. Fig. 2 shows the Raman spectrum of a fibre which had been immersed in absolute ethanol. These spectra are very similar to the spectrum of a LiDNA fibre kept at the low relative humidity of $33 \%$ as measured by Erfurth et al. ${ }^{5}$ and are characteristic of the C form of DNA.

Table 1 lists some Raman frequencies which are related to backbone vibrations and which commonly serve to identify DNA conformations. Our spectra do not show a maximum at 807 or $835 \mathrm{~cm}^{-1}$, whereas the band due to the phosphodiester semi double bond is found to have its maximum at $1102 \mathrm{~cm}^{-1}$, the line being lower and broader than in the A or B form spectrum. Usually in literature the $C$ form is identified only by an unassigned broad band at $884 \mathrm{~cm}^{-1}$ in the Raman spectrum, ${ }^{4,5}$ which may be present in Fig. 1 but is obscured in Fig. 2 by an ethanol contribution at $883 \mathrm{~cm}^{-1}$ due to the $\mathrm{C}-\mathrm{C}-\mathrm{O}$ stretch. However, our spectra show more differences from the spectrum of a typical A or B form and these can serve to identify the DNA conformation.

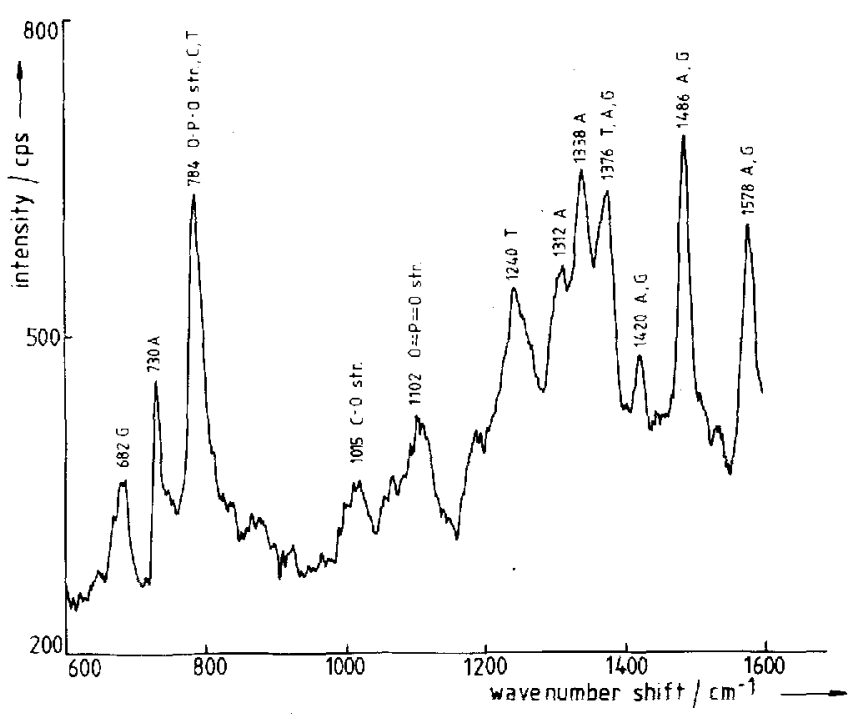

Figure 1. Raman spectrum of a LiDNA fibre in contact with ethanol vapour. Laser power at sample, $10 \mathrm{~mW}$; resolution, $3.2 \mathrm{~cm}^{-1}$; interval, $2 \mathrm{~cm}^{-1}$; counting time, $25 \mathrm{~s}$.

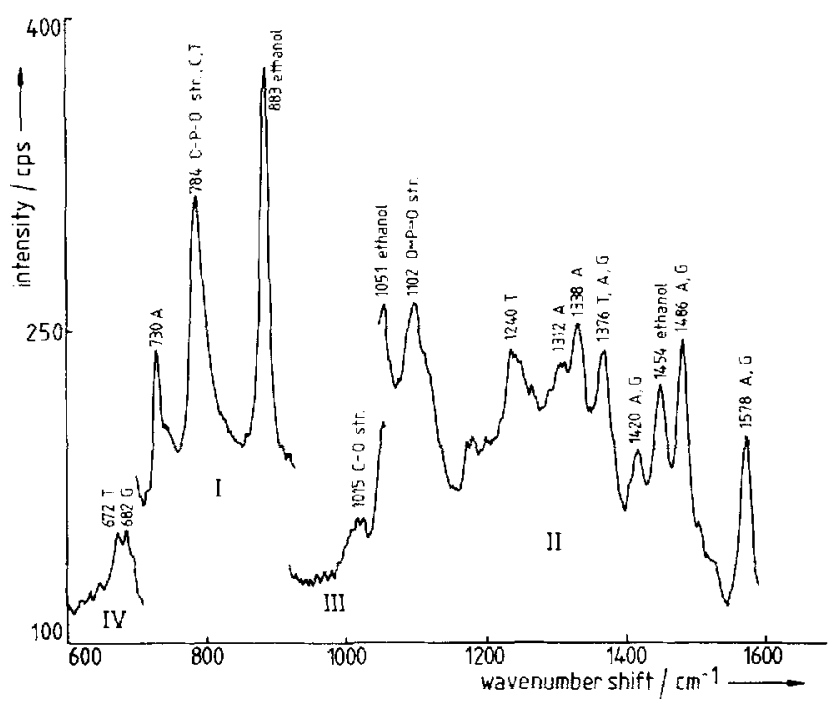

Figure 2. Raman spectrum of a LiDNA fibre immersed in absolute ethanol. The Roman numerals denote the time sequence in which the parts of the spectrum were recorded. Experimental data as in Fig. 1.

When we compare the base frequencies in our spectra with those in a $B$ form spectrum we find the following differences: the thymine line at $751 \mathrm{~cm}^{-1}$ is only visible as a shoulder on the slope of the $730 \mathrm{~cm}^{-1}$ adenine band; in the $1200-1300 \mathrm{~cm}^{-1}$ region a thymine line is recorded at $1240 \mathrm{~cm}^{-1}$ which is broadened on its high-frequency side, whereas in the $B$ form the broadening is on the low-frequency side, and a maximum at $1259 \mathrm{~cm}^{-1}$ due to cytosine and adenine is also found broadened at the low-frequency side; between 1300 and $1400 \mathrm{~cm}^{-1}$ three lines associated with bases are found. In the $B$ form they are centred at $1303 \mathrm{~cm}^{-1}$ (A), $1340 \mathrm{~cm}^{-1}$ (A) and $1378 \mathrm{~cm}^{-1}(\mathrm{~T}, \mathrm{~A}, \mathrm{G})$. In our spectra these maxima are

Table 1. Some backbone frequencies characteristic of DNA conformations

\begin{tabular}{|c|c|c|}
\hline Conformation & $\begin{array}{l}\text { Characteristic backbone } \\
\text { vibrations }\left(\mathrm{cm}^{-1}\right)\end{array}$ & Examples \\
\hline \multirow[t]{4}{*}{ A } & 807 (O-P-O & \\
\hline & $\begin{array}{l}\text { symmetric } \\
\text { stretch) }\end{array}$ & $\begin{array}{l}\text { 1. NaDNA fibres in } \\
\text { ethanol-water mixtures } \\
\text { containing more than } \\
72 \text { vol. } \% \text { of ethanol }\end{array}$ \\
\hline & $\begin{array}{c}1100 \quad \text { (Oت-P }=0 \\
\text { symmetric } \\
\text { stretch) }\end{array}$ & $\begin{array}{l}\text { 2. Low-salt } \mathrm{NaDNA} \text { fibres } \\
\text { at relative humidity } \\
\text { between } 75 \text { and } 92 \%\end{array}$ \\
\hline & & $\begin{array}{l}\text { 3. High-salt NaDNA in } \\
\text { solution }\end{array}$ \\
\hline \multirow[t]{2}{*}{ B } & $\begin{array}{l}835 \text { (O-P-O } \\
\text { anti- } \\
\text { symmetric } \\
\text { stretch) }\end{array}$ & $\begin{array}{l}\text { 1. Low-salt NaDNA in } \\
\text { solution }\end{array}$ \\
\hline & 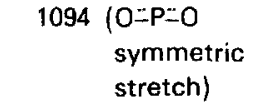 & $\begin{array}{l}\text { 2. Low-salt NaDNA fibres } \\
\text { at relative humidity } \geqslant \\
92 \%\end{array}$ \\
\hline \multirow[t]{2}{*}{ c } & $\begin{array}{l}884 \text { (unassigned } \\
\text { broad band) }\end{array}$ & $\begin{array}{l}\text { 1. Low-salt LiDNA fibres at } \\
\text { relative humidity } \leqslant 33 \%\end{array}$ \\
\hline & $\begin{array}{l}1102 \text { (Oت̈P }=0 \\
\text { symmetric } \\
\text { stretch) }\end{array}$ & $\begin{array}{l}\text { 2. Low-salt LiDNA fibres in } \\
\text { contact with ethanol- } \\
\text { water mixtures } \\
\text { containing at least } \\
95 \text { vol. } \% \text { of ethanol }\end{array}$ \\
\hline
\end{tabular}




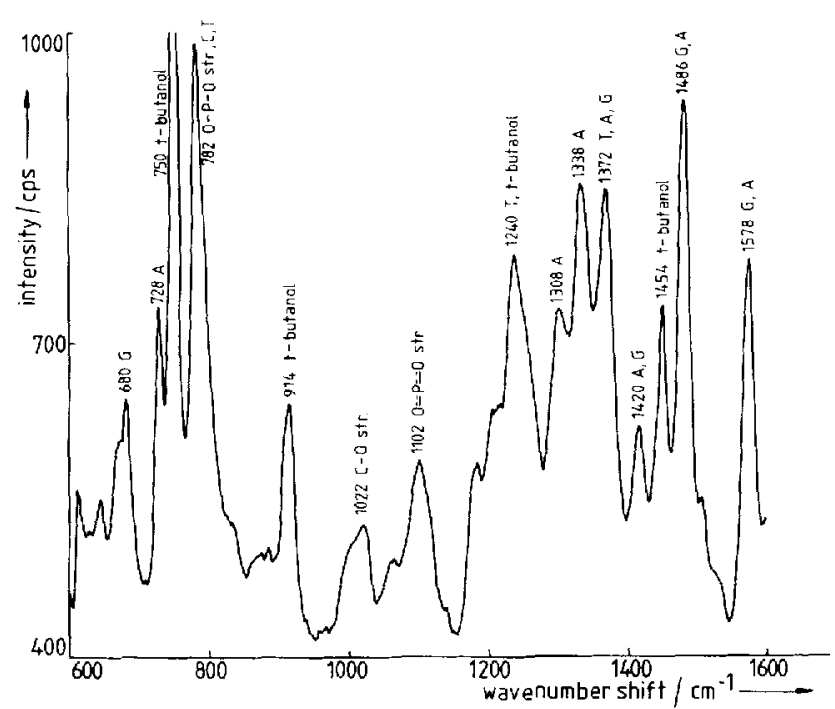

Figure 3. Raman spectrum of a LiDNA fibre soaked in tert-butanol. Experimental data as in Fig. 1.

found at 1312/1308, 1338 and $1376 / 1372 \mathrm{~cm}^{-1}$. Apart from these small frequency shifts, we notice that the $1338 \mathrm{~cm}^{-1}$ band has the highest intensity, whereas in the $B$ spectrum the maximum intensity is always found at $1378 \mathrm{~cm}^{-1}$

It should be noted that these differences are probably specific for calf thymus DNA. When a different base composition is present the characteristics may change. When we compare the measured spectrum with an $\mathrm{A}$ form spectrum, a list of significant differences can also easily be made. The spectrum of the fibre when soaked in $99.8 \%$ ethanol contains alcohol contributions. The intensity of these could be reduced by recording the depolarized spectrum. Because of the high degree of polarization of some ethanol lines the reduction is so effective that it is not necessary to subtract the ethanol contributions from the spectrum and the DNA bands are easily recognized.

Fig. 3 shows the spectrum of the fibre in tert-butanol. It has the same properties as the previous spectra although the intensity of the T, A, G line, now centred at $1372 \mathrm{~cm}^{-1}$, is not decreased to the same extent and the $1240 \mathrm{~cm}^{-1} \mathrm{~T}$ line contains a contribution from tertbutanol. When we used tert-butanol which was not absolutely free from water, the intensity of the $1372 \mathrm{~cm}^{-1}$ band was greater than that of the $1338 \mathrm{~cm}^{-1}$ line, which indicates that the $\mathrm{B}$ conformation was then adopted. During the experiments the fibre was soaked in tertbutanol which was just above its melting point and in this case we did not suppress the alcohol lines by recording the depolarized spectrum.

The spectra did not change after illumination of the sample for $4 \mathrm{~h}$.

\section{DISCUSSION}

Raman spectroscopy is a useful technique for studying the conformation of DNA under various conditions, especially when a microprobe is used. This offers a number of advantages: the microscope objective allows effective collection of the scattered light; owing to the small size of the laser spot very little material is required; the laser beam can be focused on to a part of the fibre which contains little free alcohol so that the intensity of the interfering alcohol lines is relatively low.

We were therefore able to record accurately the spectra of a LiDNA fibre in ethanol and tert-butanol. It is not necessary to subtract the ethanol lines and the background spectrum as Martin and Wartell ${ }^{2}$ had to do. In their study of the $B \rightarrow A$ transition of NaDNA in ethanol-water mixtures, the $883 \mathrm{~cm}^{-1}$ ethanol peak height was 3-4 times that of the $784 \mathrm{~cm}^{-1}$ DNA band. Further, some ethanol lines could be reduced in intensity by recording the depolarized spectrum. In that case we did not observe changes in the relative intensities of the DNA bands. We also have shown that it is allowed to let the excess ethanol evaporate; as long as the fibre stays in contact with the vapour no conformational changes are observed.

Our spectra of the fibres in liquid ethanol and in contact with ethanol vapour are in good agreement with the spectrum of the LiDNA fibre at a relative humidity of $33 \%, 5$ which is in the $\mathrm{C}$ conformation as shown by $x$-ray experiments. ${ }^{6}$ Therefore, we conclude that our samples have also adopted the $\mathrm{C}$ form. The spectrum of the fibre in tert-butanol, however, does not exhibit the properties of the $C$ form so strongly and when the tert-butanol is not absolutely free from water the spectrum immediately shows B properties. Therefore, it is likely that in this case the conformation lies between the $B$ and $C$ forms, which should be considered as extremes.

Our experiments with ethanol confirm the conclusions of the x-ray studies performed by Zimmerman and Pheiffer ${ }^{1}$ that the fibre adopts the $C$ form when in contact with an ethanol-water mixture which contains at least 95 vol. $\%$ ethanol. They also observer this conformation in a 95 vol. $-\%$ tert-butanol- 5 vol. $\%$ water mixture. This is not supported by our measurements.

It is difficult to indicate precisely what happens on a molecular scale during the $\mathrm{B} \rightarrow \mathrm{C}$ transition, but some comments can be made. It should be noted that only adenine and thymine bands show large changes in intensity and to a less extent in frequency. Drew and Dickerson, ${ }^{7}$ who obtained x-ray data from

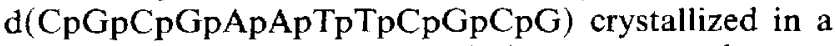
$B$-form double helix of two dodecamer strands, suggested that the $B$ conformation is stabilized by a regular spine of water molecules in the minor groove in $\mathrm{A}+$ T-rich segments of the helix. This may explain that on dehydration, by replacing the water by alcohol, mainly the thymine and adenine bands in the Raman spectrum are submitted to changes. They found that the water molecules are attached to the adenine $\mathrm{N}-3$ and the thymine $\mathrm{O}-2$ position.

It is remarkable that in the spectrum of calf thymus DNA in $D_{2} \mathrm{O}$ the intensity of T, A band at $1375 \mathrm{~cm}^{-1}$ is much lower than that of the $1340 \mathrm{~cm}^{-1}$ adenine line. This resembles one of our observations. However, we do not yet understand what relationship may exist between deuterium exchange (N-3-D in thymine, C-6$\mathrm{ND}_{2}$ in adenine) and dehydration by substitution of water by alcohol.

\section{Acknowledgement}

Part of this work was supported by the Netherlands Organization for the Advancement of Pure Research (Z.W.O.). 


\section{REFERENCES}

1. S. B. Zimmerman and B. H. Pheiffer, J. Mol. Biol. 142, 315 (1980).

2. J. C. Marvin and R. M. Wartell, Biopolymers 31, 499 (1982).

3. S. B. Zimmerman and B. H. Pheiffer, J. Mol. Biol. 135, 1023 (1979).

4. D. C. Goodwin and J. Brahms, Nucleic Acids Res. 5, 835 (1978).

5. S. C. Erfurth, E. J. Kiser and W. L. Peticolas, Proc. Nati. Acad. Sci. USA 69, 938 (1972).
6. Q. A. Marvin, M. Spencer, M. H. F. Wilkins and L. D. Hamilton, J. Mol. Biol. 3, 547 (1961).

7. H. R. Drew and R. E. Dickerson, J. Mol. Biol. 151, 535 (1981).

Received 24 September 1984 